\title{
ANALISIS PENDAPATAN PEDAGANG TANAMAN HIAS PADA DAERAH SENTRA DAN NON-SENTRA DI KECAMATAN TAWANGMANGU
}

\author{
Niken Ambarwati*, Eny Lestari dan Mei Tri Sundari \\ Program Studi Agribisnis, Fakultas Pertanian, Universitas Sebelas Maret \\ *Corresponding author: niken.ambarwati@student.uns.ac.id
}

\begin{abstract}
The purpose of this study is to analyze the income of ornamental plant traders living in the central area (Nglurah) and non-centers (Kalisoro and Ngledoksari). The main method of this research is descriptive analysis. The location of this research is intentional (purposive), by selecting Tawangmangu District as the research location. The method of determining the respondents was done accidentally (accidental sampling) to 30 traders of ornamental plants of the central area and 30 traders of ornamental plants of non-central areas. Data used in this research are primary data and secondary data. The data analysis method used is income analysis, multiple linear regression analysis, F test, and T-test. Based on earnings analysis shows the average total cost of local traders in the central region of 8,508,364.62 IDR with income of 14,330,849.82 IDR and income of 5,822,485.20 IDR. The average number of cost traders in non-central areas is 7,983,978.00 IDR with revenue of 14,590,483.33 IDR, and income of 6,606,505.33 IDR. The result of T-test shows that the income of ornamental plant traders in the central area is influenced by the experience of trading $\left(X_{2}\right)$, venture capital $\left(X_{3}\right)$, and land area $\left(X_{6}\right)$. While traders of ornamental plants in non-central areas are influenced by the experience of trading $\left(X_{2}\right)$, venture capital $\left(X_{3}\right)$, and labor in the family $\left(X_{5}\right)$.
\end{abstract}

Keywords: Central area; Income analysis; Non-central region; Ornamental plants traders; Ornamental plants

Cite this as: Ambarwati, N., Lestari, E., \& Sundari, M. 2017. Analisis Pendapatan Pedagang Tanaman Hias pada Daerah Sentra dan Non-Sentra di Kecamatan Tawangmangu. Caraka Tani: Journal of Sustainable Agriculture. 32(2), 84-94. doi: http://dx.doi.org/10.20961/carakatani.v32i2.13478

\section{PENDAHULUAN}

Tanaman hias yang termasuk dalam subsektor hortikultura telah berperan sebagai sumber pendapatan dengan nilai tambah bagi petani. Tanaman hias digunakan untuk menghias bagian dalam atau luar suatu bangunan. Menurut Ratnasari (2007), baik tanaman hias daun maupun bunga dapat tumbuh dengan baik bila dibudidayakan di kondisi lingkungan yang tepat, seperti ketinggian tempat, kebutuhan air, dan cahaya. Ketinggian tempat rata-rata di kecamatan Tawangmangu adalah $1236 \mathrm{mdpl}$ (BPS, 2015). Tawangmangu termasuk dalam kategori dataran tinggi yang cocok bagi budidaya tanaman hias.

Berdasarkan Dinas Pertanian Kabupaten Karanganyar (2014), Kecamatan Tawangmangu menghasilkan produksi beberapa tanaman hias lebih tinggi daripada kecamatan lainnya. Potensi produksi tanaman hias di Kecamatan
Tawangmangu dimanfaatkan untuk berdagang tanaman hias. Pedagang tanaman hias tersebar di beberapa tempat di Kecamatan Tawangmangu, yaitu Daerah Sentra (Nglurah) dan Non Sentra (Ngledoksari dan Kalisoro).

Adanya lokasi Sentra Tanaman Hias ini membuat peneliti tertarik untuk meneliti lebih lanjut apakah terdapat perbedaan pendapatan dalam berdagang tanaman hias antara warga di daerah sentra dan non sentra. Peneliti juga ingin mengetahui lebih lanjut faktor-faktor yang mempengaruhi pendapatan pedagang tanaman hias di daerah sentra dan non sentra.

\section{METODE PENELITIAN}

Penelitian ini menggunakan metode dasar deskriptif analitis. Metode ini memiliki fokus pada pemecahan masalah aktual yang diawali dengan pengumpulan data-data, kemudian 
disusun, dijelaskan dan dianalisis (Surakhmad 2004). Penentuan lokasi penelitian dilakukan secara sengaja (purposive), yaitu didasarkan dengan pertimbangan bahwa Kecamatan Tawangmangu menghasilkan produksi tanaman hias lebih besar daripada Kecamatan lain di Kabupaten Karanganyar.

Metode penentuan responden dilakukan secara kebetulan (accidental). Sampel pada penelitian ini yaitu pedagang tanaman hias masing-masing daerah sentra dan non sentra sejumlah 30 orang. Penelitian ini dilakukan pada bulan Oktober November 2016.

Data yang digunakan dalam penelitian adalah data primer dan sekunder. Data primer diperoleh dari melalui wawancara dengan kuisioner dan observasi terhadap pedagang tanaman hias, dan data sekunder diperoleh dari BPS, seperti data produksi tanaman hias. Analisis data yang digunakan adalah analisis pendapatan, dan analisis faktor-faktor yang mempengaruhi pendapatan pedagang tanaman hias pada daerah sentra dan non sentra.

Perhitungan analisis pendapatan usahatani pada daerah sentra dan non-sentra tanaman hias digunakan rumus: $\mathrm{Pd}=\mathrm{TR}+\mathrm{TC}$. Analisis faktorfaktor diperoleh dengan menggunakan uji regresi linier berganda, pengujian statistik yang meliputi koefisien determinasi $\left(\mathrm{R}^{2}\right)$, uji $\mathrm{F}$ serta uji $\mathrm{T}$, dan pengujian asumsi klasik.

Faktor-faktor yang diteliti termasuk dalam faktor internal yang mempengaruhi pendapatan. Menurut Suratiyah (2015), faktor internal yang mempengaruhi pendapatan adalah variabel umur, pengalaman berdagang, modal usaha, tingkat pendidikan, dan tenaga kerja dalam keluarga.

Analisis yang digunakan untuk mengetahui faktor-faktor yang mempengaruhi pendapatan pedagang tanaman hias pada daerah sentra dan non-sentra adalah menggunakan uji regresi yang didukung dengan program SPSS 17.0. Secara matematis dapat dirumuskan dalam persamaan berikut:

a. Fungsi Produksi Daerah Sentra

$\mathrm{Y}=\propto+\beta_{1} X_{1}+\beta_{2} X_{2}+\beta_{3} X_{3}+\beta_{4} X_{4}+\beta_{5} X_{5}+\beta_{6} X_{6}+e$

b. Fungsi Produksi Daerah Non-sentra

$$
\mathrm{Y}=\propto+\beta_{1} X_{1}+\beta_{2} X_{2}+\beta_{3} X_{3}+\beta_{4} X_{4}+\beta_{5} X_{5}+\beta_{6} X_{6}+e
$$

Keterangan:

$$
\begin{aligned}
& \mathrm{Y}=\text { pendapatan pedagang tanaman hias } \\
& \propto \quad=\text { nilai konstanta } \\
& \beta_{1}-\beta_{6}=\text { koefisien regresi } \\
& X_{1} \quad=\text { variabel umur pedagang (tahun) } \\
& X_{2} \quad=\text { variabel pengalaman berdagang } \\
& \text { tanaman hias (tahun) } \\
& X_{3} \quad=\text { variabel modal usaha }(\mathrm{Rp}) \\
& X_{4} \quad=\text { variabel tingkat pendidikan (tahun) } \\
& X_{5} \quad=\text { variabel tenaga kerja dalam keluarga } \\
& \text { (orang) } \\
& X_{6}=\text { variabel luas lahan }(\mathrm{m} 2) \\
& e \quad=\text { error }
\end{aligned}
$$

Pengukuran seberapa jauh kemampuan model dalam menjelaskan variasi variabel bebas diukur dengan koefisien determinasi $\left(R^{2}\right)$. Nilai $R^{2}$ berkisar antara nol sampai satu, dimana nilai $\mathrm{R}^{2}$ yang kecil berarti kemampuan variabel-variabel bebas dalam menjelaskan variabel terikat amat terbatas. Pengaruh keseluruhan variabel bebas terhadap variabel terikat dapat diketahui dengan melakukan uji $\mathrm{F}$, dan dalam penelitian ini tingkat kepercayaan $95 \%(\alpha=0,05)$. Hasil nilai F hitung
> F tabel, maka secara bersama-sama variabel bebas berpengaruh nyata terhadap variabel terikat, sebaliknya jika $\mathrm{F}$ hitung $\leq \mathrm{F}$ tabel maka secara bersama-sama variabel bebas tidak berpengaruh nyata terhadap variabel terikat. Pengujian pengaruh masing-masing variabel bebas terhadap variabel terikat digunakan uji $\mathrm{t}$ dengan tingkat kepercayaan 95\% $(\alpha=0,05)$. Hasil t signifikansi $\alpha<0,05$ maka secara parsial variabel bebas berpengaruh nyata terhadap variabel terikat, sebaliknya jika t signifikansi $\alpha \geq 0,05$ maka secara parsial variabel bebas tidak berpengaruh nyata terhadap variabel terikat (Arianti et al., 2010).

Pengujian asumsi klasik dengan menggunakan uji sebagai berikut:

1) Uji Multikolinearitas

Uji multikolieneritas dilakukan untuk mengetahui apakah ada hubungan antar variabel bebas. Uji multikolieneritas dapat dilakukan dengan melihat nilai TOL (Tolerance) dan Variance Inflation Faktor (VIF) dari masing-masing variabel bebas terhadap variabel terikatnya. Apabila VIF dan 
TOL $<10$, maka model dinyatakan bebas dari gejala multikolinearitas (Suliyanto, 2011).

2) Uji Heteroskedastisitas

Menurut Suliyanto (2011), suatu model regresi dikatakan terjadi heteroskedastisitas jika di dalam model tersebut terdapat varian variabel yang tidak sama (konstan). Uji heteroskedastisitas dapat dilakukan menggunakan uji Park Gleyser dengan cara mengorelasikan nilai absolute residualnya dengan masing-masing variabel bebas. Jika hasil nilai probabilitasnya memiliki nilai signifikansi > nilai alpha -nya $(0,05)$, maka model tidak mengalami heteroskedastisitas.

3) Uji Autokorelasi

Uji autokorelasi bertujuan untuk mengetahui apakah terdapat korelasi yang sempurna antara anggota-anggota observasi. Pendeteksiannya dengan menggunakan Durbin Watson Test. Menurut Gujarati (2006), kriteria pengujian sebagai berikut:

a) $\mathrm{dU}>\mathrm{DW}<4$-dU berarti tidak terjadi autokorelasi.

b) $\mathrm{dL}>\mathrm{DW}<\mathrm{dU}$ atau $4-\mathrm{dU}<\mathrm{DW}<4-\mathrm{dL}$ berarti tidak dapat disimpulkan (inconclusive).

c) $\mathrm{DW}<\mathrm{dL}$ atau DW $>4$-dL artinya terjadi autokorelasi.

\section{HASIL DAN PEMBAHASAN}

\section{Gambaran Usaha Tanaman Hias}

Lokasi usaha pedagang daerah sentra seharusnya yang utama berada di Dukuh Nglurah, akan tetapi penamaan lokasi yang ada di gapura masuk lokasi tersebut tidak berfungsi sebagaimana mestinya. Hal ini dikarenakan di Dukuh Nglurah, tidak disediakan tempat kios khusus pedagang untuk berjualan. Sebagian besar pedagang tanaman hias daerah sentra merupakan penduduk yang tinggal dan menetap disana.

Seharusnya penamaan agrowisata sentra tanaman hias tidak sebatas nama, melainkan agar dapat berfungsi layaknya agrowisata. Menurut Hamzah et al. (2011), agrowisata yang berjalan dengan baik akan memberikan dampak kepada kehidupan sosial warga yaitu menjadi lebih terberdayakan, dan lapangan pekerjaan bertambah. Dampak perekonomian dapat dirasakan warga tidak hanya yang menjual tanaman hias, melainkan warga lain yang turut berpartisipasi bekerja dalam lingkup agrowisata seperti penjual makanan, minuman, penjaga tiket masuk, petugas kebersihan, dan lain-lain.

Sementara pedagang tanaman hias pada daerah non sentra yaitu Dukuh Kalisoro dan Ngledoksari berjualan di rumah, lokasi wisata, dan di luar Kecamatan Tawangmangu. Pedagang daerah non sentra tidak berjualan di daerah sentra karena mereka tidak tinggal di Dukuh Nglurah. Pedagang tanaman hias pada daerah non sentra sebagian besar berjualan di luar Kecamatan Tawangmangu karena dinilai dapat menghasilkan pendapatan yang lebih baik.

Jenis tanaman yang dijual responden secara umum dapat dikelompokkan menjadi tanaman hias bunga dan tanaman hias daun. Termasuk dalam tanaman hias bunga yang dijual adalah: Mawar, Anggrek, Krisan, Dahlia, Melati Jepang, Anthurium Bunga, Lavender, Euphorbia, Cempaka Merah, dan lain-lain. Jenis tanaman hias daun yang dijual adalah: Aglaonema, Puring, Cemara, Jemani, Pucuk Merah, Brokoli Hias, Palem, dan sebagainya. Beragamnya jenis tanaman yang dijual oleh pedagang tanaman hias didasarkan karena konsumen mereka adalah konsumen akhir, yaitu konsumen yang membeli tanaman hias untuk dimiliki sendiri atau tidak untuk dijual lagi. Bervariasinya tanaman yang dijual juga berlaku pada pedagang tanaman hias keliling yang menggendong tanaman hias. Responden pedagang keliling menuturkan, jumlah tanaman yang mereka beli dari pengepul masing-masing tanaman sedikit, tapi dengan banyak ragam/variasi tanaman.

Tanaman hias yang dijual oleh responden pedagang tanaman hias berasal dari petani tanaman hias, dan adapula sebagian responden yang membudidayakan tanaman hias dengan pembibitan atau melakukan stek dan pemotongan tunas-tunas dari tanaman sebelumnya sehingga mereka mempunyai untung yang lebih besar. Pedagang tanaman hias yang berjualan keliling atau dipikul biasanya membeli tanaman dari pengepul daerah setempat ataupun melakukan budiaya sendiri.

Kegiatan penjualan tanaman hias terjadi di lokasi pedagang keliling maupun yang memiliki kios. Artinya. konsumen datang langsung ke lokasi penjualan tanaman hias. Konsumen juga dapat memesan dalam jumlah banyak dan responden yang mengantarkan tanaman hiasnya bila dipesan dalam jumlah besar untuk keperluan menghias taman. 
Pedagang tanaman hias yang berlokasi di tempat wisata harus dapat menarik minat konsumen. Salah satu caranya adalah dengan pelayanan dan kemampuan atau keterampilan pedagang tanaman hias dalam menjelaskan tentang tanaman hias yang dijual ke konsumen. Selain itu, cara yang dilakukan adalah menata tanaman hias dengan warna dan corak yang menarik sehingga konsumen dapat datang ke kios ataupun pedagang keliling untuk membeli tanaman tersebut.

Salah satu hal yang berpengaruh terhadap keberhasilan pemasaran suatu produk pertanian adalah keberadaan saluran pemasaran, yang didefinisikan sebagai serangkaian organisasi yang saling tergantung dan terlibat dalam proses pemasaran untuk menjadikan produk atau jasa siap digunakan atau dikonsumsi (Kotler, 2000). Adanya saluran pemasaran inilah kegiatan bisnis dapat berlangsung mulai di tingkat petani sebagai produsen tanaman sampai ke konsumen akhir.
Sehingga saluran pemasaran dapat dilihat pada Gambar 1.

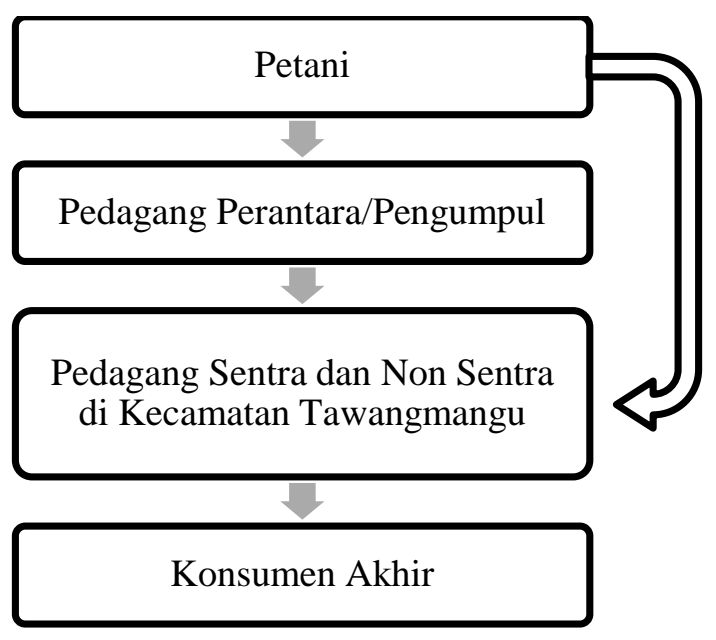

Gambar 1. Saluran Pemasaran Tanaman Hias di Kecamatan Tawangmangu

Total Biaya Usaha Tanaman Hias

Tabel 1. Rata-rata Total Biaya Usaha Tanaman Hias pada Daerah Sentra dan Non Sentra di Kecamatan Tawangmangu

\begin{tabular}{lrr}
\multicolumn{1}{c}{ Keterangan } & $\begin{array}{c}\text { Daerah Sentra } \\
\text { (Rp/Bulan) }\end{array}$ & $\begin{array}{r}\text { Daerah Non Sentra } \\
\text { (Rp/Bulan) }\end{array}$ \\
\hline 1. Biaya Tetap & & \\
a. Sewa & $22.666,67$ & $36.994,43$ \\
b. Pajak & $2.875,00$ & 720,00 \\
c. Retribusi & $9.400,00$ & $20.216,67$ \\
d. Penyusutan $\quad 33.067,95$ & $22.748,21$ \\
$\quad$ Jumlah & $\mathbf{6 5 . 1 2 4 , 6 2}$ & $\mathbf{7 9 . 9 5 9 , 3 1}$ \\
2. Biaya Variabel & & \\
a. Pembelian Tanaman Hias & $6.603 .283,25$ & $5.897 .550,00$ \\
b. Pupuk & $74.308,33$ & $62.450,00$ \\
c. Pestisida & $9.083,17$ & $9.060,56$ \\
d. Media Tanam & $52.035,00$ & $38.150,00$ \\
e. Wadah Tanaman & $82.821,92$ & $67.221,47$ \\
f. TK dalam keluarga & $935.666,67$ & $1.005 .000,00$ \\
g. TK luar keluarga & $181.667,00$ & $110.833,33$ \\
h. Transportasi & $\mathbf{5 0 1 . 5 0 0 , 0 0}$ & $\mathbf{7 1 3 . 2 0 0 , 0 0}$ \\
$\quad$ Jumlah & $\mathbf{8 . 4 4 0 . 3 6 5 , 0 0}$ & $\mathbf{7 . 9 0 3 . 4 6 5 , 3 6}$ \\
\hline \multicolumn{1}{c}{ Total Biaya } & $\mathbf{8 . 5 0 5 . 4 8 9 , 6 2}$ & $\mathbf{7 . 9 8 3 . 4 2 4 , 6 7}$ \\
\hline
\end{tabular}

Sumber: data primer diolah, 2016

Berdasarkan data dalam Tabel 1, rata-rata biaya tetap yang dibayarkan responden daerah sentra sebanyak Rp65.124,62/bulan, sedangkan responden daerah non sentra membayar sejumlah Rp79.959,31/bulan. Sebagian besar responden menyewa kios atau lahan untuk berjualan. Hal ini dapat dilihat dari biaya sewa yang lebih besar dari biaya pajak.

Biaya sewa pada responden daerah sentra ialah Rp22.666,67/bulan sedangkan pada daerah non sentra sebesar Rp36.94,43/bulan. Biaya pajak pada responden daerah sentra adalah 
Rp2.875,00/bulan dan responden daerah non sentra sebesar Rp720,00/bulan.

Biaya retribusi pada responden daerah sentra sebanyak Rp9.400,00/bulan, sedangkan responden non sentra sebanyak Rp20.216,67/bulan. Perbedaan jumlah biaya sewa/pajak dan biaya retribusi antara responden daerah sentra dan non sentra dikarenakan perbedaan lokasi jualan. Responden yang berdagang di luar Kecamatan Tawangmangu dapat mengeluarkan biaya lebih mahal daripada responden yang berjualan di Kecamatan Tawangmangu.

Biaya penyusutan dikenakan pada peralatan yang digunakan responden dalam usahanya. Biaya penyusutan responden pedagang tanaman hias tersebut kecil dikarenakan umur ekonomis yang lama, serta ada alat yang tidak dimiliki oleh semua responden sehingga ketika dicari nilai rataratanya akan kecil. Rata-rata biaya penyusutan yang ditanggung oleh responden daerah sentra adalah Rp33.057,95, sedangkan untuk daerah non sentra adalah Rp22.748,21.

Berdasarkan Tabel 1 dapat diketahui bahwa jumlah rata-rata biaya variabel pada responden daerah sentra lebih besar daripada responden daerah non sentra. Biaya pembelian tanaman hias pada responden daerah sentra sebesar Rp6.603.283,25 per bulan. Sementara responden daerah non sentra sebesar Rp5.897.550,00 per bulan. Responden dalam membeli tanaman hias ada yang dilakukan secara tunai maupun hutang. Beberapa responden yang bertindak sebagai pengepul menuturkan bahwa pedagang keliling ada yang membeli dengan berhutang, dan akan dibayar bila tanaman hias telah laku terjual. Hal ini serupa dengan kasus Bagchi et al. (2013) di Bangladesh, kasus pembelian dan penjualan tanaman hias sekitar 60\% dilakukan secara kredit dan $40 \%$ secara tunai.

Rata-rata biaya perawatan tanaman hias yang dilakukan responden daerah sentra dan non sentra. Salah satu macam biaya perawatan tanaman hias ialah biaya pupuk. Biaya pupuk yang dikeluarkan oleh responden daerah sentra sejumlah Rp73.891,67, sedangkan daerah non sentra sejumlah Rp62.450.

Perawatan tanaman hias selain pupuk, juga perlu pemberian pestisida. Biaya Pestisida dalam Tabel 1 sejumlah Rp9.083,17 pada responden tanaman hias daerah sentra, dan Rp9.060,56 pada daerah non sentra. Biaya pestisida relatif sedikit karena responden jarang memberikan pestisida pada tanamannya. Pemberian pestisida dilakukan dengan intensitas satu hingga dua bulan sekali.

Media tanam yang digunakan oleh responden ada tanah, sekam, hingga sabut kelapa. Tanah tidak dimasukkan dalam biaya perawatan karena ketersediaannya tidak membutuhkan biaya seperti sekam dan sabut kelapa. Sekam dan sabut kelapa digunakan sebagai tambahan atau media utama pada jenis tanaman tertentu.

Tanaman hias yang dijual memerlukan wadah agar mudah dibawa oleh konsumen. Umumnya tanaman hias dikemas dalam wadah polybag karena harganya yang murah, ringan, serta mudah bila ingin mengganti ke dalam pot atau ditanam di tanah. Biaya untuk membeli polybag pada responden daerah sentra adalah Rp67.521,91/bulan dan pada daerah non sentra Rp58.022/bulan. Biaya untuk pembelian pot pada pedagang daerah sentra sejumlah Rp12.800,01 dan non sentra sejumlah Rp9.199,47. Biaya keseluruhan yang dikeluarkan pedagang tanaman hias untuk wadah tanaman sejumlah Rp82.821,92 pada daerah sentra dan Rp67.221,47 pada daerah non sentra.

Meskipun biaya pembelian tanaman hias pada responden daerah sentra lebih banyak dari daerah non sentra, tetapi jumlah biaya tenaga kerja lebih besar di daerah non sentra. Hal ini terjadi karena ada responden yang berdagang dengan jenis tanaman berharga tinggi dan membutuhkan perawatan khusus. Perawatan khusus tersebut membuat responden daerah non sentra mengeluarkan biaya tenaga kerja lebih banyak yaitu sebesar Rp1.005.000,00 pada tenaga kerja dalam keluarga dan Rp110.833,33 pada tenaga kerja luar keluarga. Sementara responden daerah sentra mengeluarkan biaya tenaga kerja sebesar Rp181.667,00 untuk tenaga kerja luar keluarga dan Rp935.666,67 untuk tenaga kerja dalam keluarga.

Biaya transportasi merupakan biaya yang dikeluarkan oleh responden pedagang tanaman hias untuk keperluan jasa transportasi membeli tanaman hias. Pembelian tanaman hias dilakukan responden di beberapa tempat seperti Malang, Bogor, serta Bandung. Responden daerah sentra mengeluarkan biaya transportasi sebesar Rp501.500,00 per bulan, sementara di daerah non sentra sebesar Rp713.200,00.

Rata-rata total biaya usaha tanaman hias pada daerah sentra sejumlah Rp8.505.489,63/bulan, sedangkan pada daerah non sentra sejumlah Rp7.983.424,67/bulan. Rata-rata biaya usaha 
tersebut terdiri dari biaya tetap dan variabel. Biaya tetap pada daerah sentra sebesar Rp65.124,62/bulan dan biaya variabel sebesar Rp8.505.489,63/bulan. Rata-rata biaya tetap pada daerah non sentra sebesar Rp79.959,31/bulan dengan biaya variabel sebesar Rp7.983.424,67/bulan.

\section{Penerimaan Usaha Tanaman Hias}

Penerimaan pedagang tanaman hias diperoleh dari hasil penjualan tanaman hias dikalikan dengan harga jual tanaman. Harga jual tanaman yang berbeda-beda setiap pedagang membuat penerimaannya pun berbeda. Rata-rata penerimaan usaha tanaman hias dapat dilhat dalam Tabel 2.

Tabel 2. Rata-rata Penerimaan Usaha Tanaman Hias Pada Daerah Sentra dan Non Sentra

\begin{tabular}{|c|c|c|c|}
\hline \multirow{2}{*}{ No. } & \multirow{2}{*}{ Keterangan } & Daerah Sentra & Daerah Non Senra \\
\hline & & Jumlah & Jumlah \\
\hline 1. & Nilai Fisik Tanaman Hias (pohon) & $1.098,80$ & $1.143,43$ \\
\hline 2. & Rata-rata Harga jual per tanaman (Rp) & $12.859,04$ & $12.760,24$ \\
\hline & Total Penerimaan (Rp/Bulan) & $14.129 .516,49$ & $14.590 .483,33$ \\
\hline
\end{tabular}

Berdasarkan Tabel 2, diketahui bahwa jumlah penjualan tanaman hias pada responden daerah non sentra lebih banyak daripada responden daerah sentra. Responden daerah non sentra menjual tanaman hias sebanyak $1.143,33$ pohon dengan penerimaan sebesar Rp14.590.483,33 per bulan. Sementara responden daerah sentra menjual tanaman hias sebanyak Rp1.098,80 dengan penerimaan sebesar Rp14.129.516,49 per bulan.

\section{Pendapatan Usaha Tanaman Hias}

Pendapatan merupakan selisih antara penerimaan dengan biaya-biaya yang dikeluarkan dalam menjalankan usaha tanaman hias. Jumlah pendapatan ditentukan oleh nilai penerimaan dan biaya yang dikeluarkan. Perhitungan pendapatan pedagang tanaman hias dapat dilihat dalam Tabel 3.

Tabel 3. Rata-rata Pendapatan Responden Pedagang Tanaman Hias pada Daerah Sentra dan Non Sentra di Kecamatan Tawangmangu

\begin{tabular}{lrr}
\hline \multicolumn{1}{c}{ Keterangan } & \multicolumn{1}{c}{$\begin{array}{c}\text { Daerah Sentra } \\
\text { (Rp/Bulan) }\end{array}$} & $\begin{array}{r}\text { Daerah Non Sentra } \\
\text { (Rp/Bulan) }\end{array}$ \\
\hline Penerimaan Tanaman Hias & $\mathbf{1 0 . 2 2 1 . 4 7 5 , 0 0}$ & $\mathbf{1 4 . 5 9 0 . 4 8 3 , 3 3}$ \\
1. Biaya Tetap & $22.666,67$ & $36.994,43$ \\
a. Sewa & $2.875,00$ & 720,00 \\
b. Pajak & $9.400,00$ & $20.216,67$ \\
c. Retribusi & $33.067,95$ & $22.748,21$ \\
d. Penyusutan & $65.124,62$ & $79.959,31$ \\
$\quad$ Jumlah & & \\
2. Biaya Variabel & $6.603 .283,25$ & $5.897 .550,00$ \\
a. Pembelian Tanaman Hias & $74.308,33$ & $62.450,00$ \\
b. Pupuk & $9.083,17$ & $9.060,56$ \\
c. Pestisida & $52.035,00$ & $38.150,00$ \\
d. Media Tanam & $82.821,92$ & $67.221,47$ \\
e. Wadah Tanaman & $935.666,67$ & $1.005 .000,00$ \\
f. TK dalam keluarga & $181.667,00$ & $110.833,33$ \\
g. TK luar keluarga & $501.500,00$ & $713.200,00$ \\
h. Transportasi & $8.440 .365,00$ & $7.903 .465,36$ \\
$\quad$ Jumlah & $\mathbf{8 . 5 0 5 . 4 8 9 , 6 2}$ & $\mathbf{7 . 9 8 3 . 4 2 4 , 6 7}$ \\
Total Biaya & $\mathbf{5 . 8 2 5 . 3 6 0 , 2 0}$ & $\mathbf{6 . 6 0 7 . 0 5 8 , 6 7}$ \\
\hline \multicolumn{1}{c}{ Pendapatan } & & \\
\hline
\end{tabular}

Sumber: data primer diolah, 2016 
Berdasarkan Tabel 3 dapat diketahui rata-rata pendapatan pedagang tanaman hias pada daerah sentra dan non sentra. Rata-rata pendapatan yang diperoleh pedagang tanaman hias pada daerah sentra berjumlah Rp5.624.026,86/bulan, sedangkan pada daerah non sentra memperoleh Rp6.607.058,67/bulan. Perbedaan pendapatan yang diperoleh tersebut dapat terjadi karena perbedaan harga jual tanaman pada masingmasing pedagang, serta keefektifan pedagang dalam mengelola usahanya.

Rata-rata pendapatan pedagang tanaman hias daerah non sentra dapat lebih besar karena jumlah penerimaan yang besar serta pengeluaran biaya yang lebih kecil dari pedagang daerah sentra.

\section{Analisis Faktor - Faktor yang Mempengaruhi Pendapatan Pedagang Tanaman Hias pada Daerah} Sentra dan Non Sentra

Tabel 4. Hasil Analisis Faktor Pendapatan Pedagang Tanaman Hias Pada Daerah Sentra

\begin{tabular}{lrrr}
\hline \multicolumn{1}{c}{ Variabel } & Koefisien & Sig & VIF \\
\hline Konstanta & 4843392,363 & 0,254 & \\
Umur $\left(\mathrm{X}_{1}\right)$ & $140913,441^{\text {ns }}$ & 0,058 & 6,202 \\
Pengalaman Berdagang $\left(\mathrm{X}_{2}\right)$ & $-206607,217^{*}$ & 0,010 & 6,985 \\
Modal $\left(\mathrm{X}_{3}\right)$ & $1,097^{*}$ & 0,001 & 1,433 \\
Tingkat Pendidikan $\left(\mathrm{X}_{4}\right)$ & $-431899,545^{\mathrm{ns}}$ & 0,233 & 1,650 \\
Tenaga Kerja Dalam Keluarga $\left(\mathrm{X}_{5}\right)$ & $-11206,045^{\text {ns }}$ & 0,907 & 1,404 \\
Luas Lahan $\left(\mathrm{X}_{6}\right)$ & $2763,884^{*}$ & 0,008 & 1,119 \\
\hline $\mathrm{R}^{2}$ square $=0,784$ & & & \\
Adjusted R-square $=0,728$ & & & \\
Durbin Watson $=1,437$ & & & \\
Fhitung $=13,911>$ F tabel $=2,375$ & & &
\end{tabular}

Sumber: data primer diolah, 2016

Tabel 4 menunjukkan bahwa nilai koefisien determinan $\left(\mathrm{R}^{2}\right)$ sebesar $78,4 \%$ mempunyai arti bahwa $78,4 \%$ keragaman pendapatan usaha tanaman hias dapat diterangkan oleh umur pedagang $\left(\mathrm{X}_{1}\right)$, pengalaman berdagang $\left(\mathrm{X}_{2}\right)$, modal usaha $\left(\mathrm{X}_{3}\right)$, tingkat pendidikan $\left(\mathrm{X}_{4}\right)$, tenaga kerja dalam keluarga $\left(X_{5}\right)$, dan luas lahan $\left(X_{6}\right)$. Sementara 21,6\% sisanya dijelaskan oleh variabel lain yang tidak dimasukkan dalam model penelitian ini, seperti biaya input, curahan waktu kerja, dan lain-lain. Model yang dihasilkan dari analisis ini adalah sebagai berikut:

$$
\begin{aligned}
\mathrm{Y}= & 4843392,363+140913,441 X_{1}+ \\
& \left(-206607,217 X_{2}\right)+1,097+ \\
& \left(-431899,545 X_{4}\right)+\left(-11206,045 X_{5}\right)+ \\
& 2763,884 X_{6}+e
\end{aligned}
$$

Hasil $F_{\text {hitung }}$ sebesar 13,911 > $\mathrm{F}_{\text {tabel }}=2,375$. Artinya, variabel bebas dalam penelitian ini secara bersama-sama berpengaruh nyata terhadap pendapatan pedagang tanaman hias (Y). Hasil uji t dapat dijelaskan sebagai berikut:

1. Umur $\left(\mathrm{X}_{1}\right)$

Variabel umur dengan uji t memiliki nilai signifikansi sebesar $0,058>0,05$. Artinya, secara individu variabel umur tidak berpengaruh nyata terhadap pendapatan pedagang tanaman hias daerah sentra. Umur berkaitan dengan semangat, stamina serta kecakapan responden dalam mengelola bisnis tanaman hias. Responden yang berada pada usia senja ( $>60$ tahun) dapat berbisnis dengan baik, yang didukung dengan semangat dan stamina yang besar. Hal tersebut juga berlaku pada responden di usia produktif.

2. Pengalaman Berdagang $\left(\mathrm{X}_{2}\right)$

Variabel pengalaman berdagang dengan uji t sebesar $0,010<0,05$, artinya pengalaman berdagang berpengaruh nyata. Nilai koefisien sebesar (-206607,217), artinya apabila pengalaman berdagang bertambah 1 tahun, maka pendapatan pedagang tanaman hias pada daerah sentra akan turun sejumlah Rp206.607,217. Pengalaman pedagang yang semakin lama dan sudah merasa nyaman dengan kondisi usahanya, menyebabkan mereka enggan untuk mengadopsi inovasi yang dapat meningkatkan pendapatan. Adapun pedagang tanaman hias yang jumlahnya semakin bertambah, menyebabkan persaingan yang lebih ketat. Apabila pedagang dengan 
pengalaman berdagang lebih lama enggan untuk mengadopsi inovasi serta belum dapat menyesuaikan dengan kondisi pasar terkini, maka akan sulit bersaing sehingga menyebabkan pendapatannya akan menurun.

3. Modal Usaha $\left(\mathrm{X}_{3}\right)$

Hasil uji t sebesar 0,001 <0,05 artinya modal berpengaruh nyata terhadap pendapatan pedagang tanaman hias. Modal usaha yang dimaksud adalah modal usaha berupa uang yang digunakan untuk membeli tanaman hias. Semakin besar modal usaha, maka pedagang tanaman hias dapat membeli lebih banyak variasi dan jumlah tanamannya.

Pembelian tanaman hias dalam jumlah besar akan lebih murah harganya daripada yang jumlahnya sedikit, selain itu akan menghemat biaya transportasi pembelian tanaman. Bertambahnya jenis dan variasi tanaman dapat membuat lebih banyak konsumen yang tertarik untuk memilih dan membeli tanaman hias. Menurut Schumacher dan Marsh (2003) pedagang yang ingin meningkatkan efisiensi biaya mereka dapat mempertimbangkan memperluas operasi mereka saat ini dengan menambah modal usaha untuk mengambil keuntungan dari skala ekonomi tersebut. Perputaran modal yang baik dan lancar dalam suatu usaha juga akan meningkatkan pendapatan

4. Tingkat Pendidikan

Hasil uji t sebesar 0,233>0,05. Artinya, secara individu variabel umur tidak berpengaruh nyata terhadap pendapatan pedagang tanaman hias pada daerah sentra. Tingkat pendidikan dalam penelitian ini merupakan tingkat dalam pendidikan formal. Pada daerah sentra terdapat kelompok tani tanaman hias yang memberikan pendidikan non formal seperti penyuluhan serta pelatihan mengenai tanaman hias secara rutin. Responden daerah sentra meskipun tingkat pendidikan formalnya rendah tetapi mendapat penyuluhan serta pelatihan di kelompok tani sehingga pengetahuannya bertambah.

5. Jumlah Tenaga Kerja dalam Keluarga

Hasil uji t sebesar 0,907 > 0,05. Artinya, tenaga kerja dalam keluarga tidak berpengaruh nyata terhadap pendapatan responden daerah sentra. Variabel jumlah tenaga kerja dalam keluarga tidak berpengaruh terhadap pendapatan dikarenakan faktor tenaga kerja tidak diukur dari jumlah saja tapi kualitas dari tenaga kerja juga perlu diperhatikan.

6. Luas Lahan

Hasil uji t sebesar 0,008 $<0,05$. Artinya, luas lahan berpengaruh nyata terhadap pendapatan pedagang tanaman hias. Hal ini dikarenakan jika pedagang memiliki lahan/lokasi usaha yang lebih luas maka akan dapat menampung lebih banyak koleksi tanaman hias. Koleksi tanaman hias yang lengkap akan menarik minat pengunjung untuk membeli tanaman hias di tempat tersebut, sehingga dapat menambah pendapatan pedagang.

Tabel 5. Hasil Analisis Faktor Pendapatan Pedagang Tanaman Hias pada Daerah Non sentra

\begin{tabular}{lrrr}
\hline \multicolumn{1}{c}{ Variabel } & Koefisien & Sig & VIF \\
\hline Konstanta & $-6749005,033$ & 0,240 & \\
Umur $\left(\mathrm{X}_{1}\right)$ & $-317835,985^{\text {ns }}$ & 0,055 & 6,202 \\
Pengalaman Berdagang $\left(\mathrm{X}_{2}\right)$ & $471283,104^{*}$ & 0,007 & 6,985 \\
Modal $\left(\mathrm{X}_{3}\right)$ & $1,165^{*}$ & 0,016 & 1,433 \\
Tingkat Pendidikan $\left(\mathrm{X}_{4}\right)$ & $863237,453^{\text {ns }}$ & 0,080 & 1,650 \\
Tenaga Kerja Dalam Keluarga $\left(\mathrm{X}_{5}\right)$ & $384223,442^{*}$ & 0,008 & 1,404 \\
Luas Lahan $\left(\mathrm{X}_{5}\right)$ & $2234,588^{\text {ns }}$ & 0,228 & 1,119 \\
\hline
\end{tabular}

$\mathrm{R}^{2}$ square $=0,689$

Adjusted R-square $=0,608$

Durbin Watson $=2,052$

F-statistic $=8,510>\mathrm{F}$ tabel $=2,375$

Sumber: data primer diolah, 2010

Tabel 5 menunjukkan bahwa nilai koefisien determinan $\left(\mathrm{R}^{2}\right)$ sebesar $68,9 \%$, berarti bahwa $68,9 \%$ keragaman pendapatan usaha tanaman hias (variabel terikat $\mathrm{Y}$ ) dapat diterangkan oleh variabel-variabel bebas dalam penelitian ini. Sementara $31,1 \%$ sisanya dijelaskan oleh variabel 
lain yang tidak diteliti dalam model penelitian ini, seperti biaya input, tingkat kesuburan, curahan waktu kerja, jenis tanaman, dan lain-lain. Model yang dihasilkan dari analisis regresi ini adalah sebagai berikut:

$$
\begin{aligned}
\mathrm{Y}= & -6749005,033+\left(-317835,985 X_{1}\right)+ \\
& 471283,104 X_{2}+1,165 X_{3}+ \\
& 863237,453 X_{4}+384223,442 X_{5}+ \\
& 2234,588 X_{6}+e .
\end{aligned}
$$

Hasil $\mathrm{F}_{\text {hitung }}$ sebesar 8,510 $>\mathrm{F}_{\text {tabel }}=2,375$. Artinya, umur pedagang $\left(\mathrm{X}_{1}\right)$, pengalaman berdagang $\left(\mathrm{X}_{2}\right)$, modal usaha $\left(\mathrm{X}_{3}\right)$, tingkat pendidikan $\left(\mathrm{X}_{4}\right)$, tenaga kerja dalam keluarga $\left(\mathrm{X}_{5}\right)$, dan luas lahan $\left(\mathrm{X}_{6}\right)$ secara bersama-sama berpengaruh nyata terhadap pendapatan $(\mathrm{Y})$.

Hasil uji t dalam penelitian ini adalah sebagai berikut:

1. Umur $\left(X_{1}\right)$

Variabel umur dengan uji t memiliki nilai signifikansi sebesar $0,055>0,05$. Artinya, secara individu variabel umur tidak berpengaruh nyata terhadap pendapatan responden daerah non sentra. Umur berkaitan dengan semangat, stamina serta kecakapan responden dalam mengelola bisnis tanaman hias. Responden yang berada pada usia senja (>60 tahun) dapat berbisnis dengan baik, yang didukung dengan semangat dan stamina yang besar. Hal tersebut juga berlaku pada responden di usia produktif.

2. Pengalaman Berdagang $\left(X_{2}\right)$

Variabel pengalaman berdagang dengan uji $\mathrm{t}$ memiliki nilai signifikansi sebesar 0,007 > 0,05 . Artinya, secara individu variabel pengalaman berdagang berpengaruh positif dan signifikan, sehingga dapat menambah pendapatan pedagang tanaman hias. Pedagang yang menjalankan usaha sudah lama lebih memahami kondisi tentang pasar sehingga berdasarkan pengalaman yang sudah mereka dapatkan mereka mampu menerapkan strategistrategi pemasaran yang nantinya berdampak pada meningkatnya penjualan. Semakin lama usaha perdagangan dilakukan maka berpotensi mempunyai pelanggan tetap sehingga berpengaruh terhadap pendapatan pedagang.

3. Modal Usaha $\left(X_{3}\right)$

Hasil uji $\mathrm{t}$ memiliki nilai signifikansi sebesar 0,016 < 0,05. Artinya, modal usaha berpengaruh nyata terhadap pendapatan responden daerah non sentra. Modal usaha yang dimaksud adalah modal usaha berupa uang yang digunakan untuk membeli tanaman hias.

Pembelian tanaman hias dalam jumlah besar akan lebih murah harganya daripada yang jumlahnya sedikit, selain itu akan menghemat biaya transportasi pembelian tanaman. Bertambahnya jenis dan variasi tanaman dapat membuat lebih banyak konsumen yang tertarik untuk memilih dan membeli tanaman hias. Menurut Schumacher dan Marsh (2003) pedagang yang ingin meningkatkan efisiensi biaya dapat mempertimbangkan perluasan operasi mereka dengan menambah modal usaha untuk mengambil keuntungan. Perputaran modal yang baik dan lancar dalam suatu usaha juga akan meningkatkan pendapatan.

4. Tingkat Pendidikan $\left(\mathrm{X}_{4}\right)$

Hasil uji $\mathrm{t}$ memiliki nilai signifikansi sebesar $0,08>0,05$. Artinya, tingkat pendidikan tidak berpengaruh nyata terhadap pendapatan responden daerah non sentra. Tingkat pendidikan dalam penelitian ini merupakan tingkat dalam pendidikan formal. Responden daerah non sentra mendapat tambahan pengetahuan di luar pendidikan formal dengan mengikuti pameran serta pelatihan bisnis tanaman hias. Pengetahuan yang bertambah akan membuat responden dengan tingkat pendidikan rendah dapat mengelola usahanya dengan baik sehingga pendapatannya dapat bertambah dan bersaing dengan responden yang tingkat pendidikannya tinggi.

5. Jumlah Tenaga Kerja Keluarga $\left(\mathrm{X}_{5}\right)$

Hasil uji $\mathrm{t}$ memiliki nilai signifikansi sebesar $0,006<0,05$. Artinya, TKDK berpengaruh nyata terhadap pendapatan pedagang tanaman hias pada daerah non sentra. Hal ini menunjukkan semakin banyak tenaga kerja dalam keluarga, maka pendapatan responden akan semakin besar. Tenaga kerja dalam keluarga yang jumlahnya banyak dapat membantu kegiatan penjualan atau perawatan tanaman hias lebih baik sehingga pendapatannya akan bertambah.

6. Luas Lahan $\left(\mathrm{X}_{6}\right)$

Hasil uji $t$ memiliki nilai signifikansi sebesar 0,230 <0,05. Artinya, luas lahan tidak berpengaruh nyata terhadap pendapatan pedagang responden daerah non sentra. Luas lahan tidak berpengaruh nyata karena terdapat 
beberapa responden pedagang tanaman hias yang menjual variasi tanaman dengan harga jual tinggi ataupun langka seperti Anggrek, Cempaka Merah, Kamelia, dan sebagainya. Penjualan tanaman hias dengan harga tinggi meskipun luas lahannya sempit akan membuat pendapatannya tinggi. Hal ini dikarenakan adanya konsumen yang memiliki daya beli tinggi sehingga dapat membeli tanaman dengan harga mahal dan membuat pendapatan responden tinggi.

\section{Hasil Pengujian Asumsi Klasik}

\section{Uji Multikolinearitas}

Tabel 4 dan 5 menunjukkan nilai VIF dari masing-masing variabel bebas model persamaan daerah sentra dan non sentra. Nilai tersebut berkisar dari 1,119 sampai 6,985, yang menunjukkan tidak terjadi gejala multikolinearitas pada model persamaan di daerah sentra dan non sentra. Artinya pada model persamaan tersebut tidak terdapat hubungan antara variabel bebasnya.

2. Uji Heteroskedastisitas

Hasil dari uji Park Gleyser pada model persamaan daerah sentra dan non sentra menunjukkan bahwa probabilitas atau taraf signifikansi masing-masing variabel bernilai 1,000. Hal tersebut menunjukkan korelasi masing-masing variabel dengan nilai residualnya menghasilkan nilai lebih besar dari $\alpha(0,05)$. Artinya, model persamaan daerah sentra dan non sentra tidak mengalami gejala heteroskedastisitas.

3. Uji Autokorelasi

Berdasarkan Tabel 4, diketahui bahwa nilai Durbin Watson sebesar 1,437>0,05. Hal ini menunjukkan bahwa model persamaan daerah sentra yang digunakan tidak mengalami autokorelasi. Sementara nilai Durbin Watson pada Tabel 4 sebesar 2,052>0,05. Hal ini menunjukkan bahwa model persamaan daerah non sentra yang digunakan tidak mengalami autokorelasi.

\section{KESIMPULAN DAN SARAN}

\section{Kesimpulan}

Rata-rata pendapatan yang diperoleh pedagang tanaman hias pada daerah sentra berjumlah Rp5.624.026,86/bulan, sedangkan pedagang tanaman hias pada daerah non sentra memperoleh Rp6.607.058,67/bulan. Pendapatan pedagang tanaman hias pada daerah sentra dipengaruhi oleh faktor pengalaman berdagang, modal usaha, dan luas lahan. Sementara pendapatan pedagang tanaman hias pada daerah non sentra dipengaruhi oleh faktor pengalaman berdagang, modal usaha, dan jumlah tenaga kerja dalam keluarga.

\section{Saran}

Perlu perluasan pemasaran untuk meningkatkan pendapatan, salah satu caranya dengan mempromosikan sentra tanaman hias melalui situs pariwisata Kecamatan Tawangmangu. Perlu adanya pelatihan serta penyuluhan mengenai bisnis tanaman hias, mulai dari budidaya tanaman hias hingga pemasaran sehingga wawasan dan pengalaman pedagang mengenai bisnis tanaman hias dapat bertambah luas.

\section{DAFTAR PUSTAKA}

Arianti, N.N., Reswita, \& Fristado. 2010. Analisis Produksi dan Pendapatan Usahatani Padi pada Daerah Sentra dan Non-Sentra di Kabupaten Lebong. Jurnal Agribisnis. 2(2), 1-12.

Bagchi M., Raha S.K., \& Shunbo, Y. 2013. Supply Chain Management of Flower in Bangladesh. Metalurgia International Journal. 18(6), 153-159.

BPS (Badan Pusat Statistik). 2015. Kecamatan Tawangmangu Dalam Angka 2015. Badan Pusat Statistika Kabupaten Karanganyar. http://karanganyarkab.bps.go.id. Diakses pada 21 Desember 2015.

Dinas Pertanian Karanganyar. 2014. Tanaman Hias Karanganyar 2014. Jawa Tengah.

Gujarati, D. 2006. Dasar-Dasar Ekonometrika. Jakarta: Erlangga.

Kotler, P. 2000. Manajemen Pemasaran, Edisi Milenium. Jakarta: Prehallindo.

Hamzah, A., Yassin, A.N., Samah, B.A., D'Silva, L.J., Tiraiyaei, N., Shaffril H.A.M., \& Uli, J. 2011. Socio-Economic Impact Potential of Agro Tourism Activitie on Desa Wawasan Nelayan Community Living in Peninsular Malaysia. African Journal of Agricultural Research. 7(32), 4581-4588. doi: 10.5897/AJAR11.295.

Ratnasari. 2007. Galeri Tanaman Hias Bunga. Jakarta: Penebar Swadaya. 
Schumacher, S.K., \& Marsh T.L. 2003. Economic of Scale in the Floriculture Industry. Journal of Agricultural and Applied Economics. 35(3), 497-507.

Suliyanto. 2011. Ekonometrika Terapan. Yogyakarta: Andi Offset.

Surakhmad, W. 2004. Pengantar Penelitian Ilmiah dan Dasar Metode Teknik. Bandung: Tarsito.

Suratiyah, K. 2015. Ilmu Usahatani Edisi Revisi. Jakarta: Penebar Swadaya. 